\title{
OCCURRENCE OF MALASSEZIA YEASTS IN DERMATOLOGICALLY DISEASED DOGS
}

\author{
Sihelská, Z., Čonková, E., Váczi, P. \\ Harčárová, M., Böhmová, E. \\ Department of Pharmacology and Toxicology \\ University of Veterinary Medicine and Pharmacy, Komenského 73, 04181 Košice, \\ Slovakia \\ zuzana.sihelska@uvlf.sk
}

\section{ABSTRACT}

The Malassezia genus is represented by several lipophilic yeasts, normally present on the skin of many warm-blooded vertebrates, including humans. The aim of this study was to investigate the occurrence of Malassezia yeasts in dogs with skin lesions (dermatitis, interdigital dermatitis and inflammation of anal sacs) and otitis externa. The presence of Malassezia spp. was investigated in a group of 300 dogs exhibiting clinical manifestations. The isolates of Malassezia were identified by using phenotypic (biochemical-physiological and morphological characteristics) and genotypic methods (PCR, RFLP-AluI, BanI and MspA1I) which allowed their precise identification. Malassezia yeasts were isolated from 84 specimens obtained from 76 positive dogs. M. pachydermatis was the most frequently isolated species (79 isolates) in this study. M.furfur was identified in four dogs and M.nana in one dog. The prevalence of isolated Malassezia spp. was $25.3 \%$ in dogs with skin lesions; from which $36.0 \%$ were dogs suffering from otitis externa, $24.5 \%$ from dogs having dermatitis, $16.4 \%$ from dogs with interdigital dermatitis and $14.3 \%$ from dogs having inflammation of the anal sacs. A higher prevalence of Malassezia spp. was observed in animals with pendulous ears in comparison with dogs having erect ears.

Key words: dermatitis; diagnostics; dogs; Malassezia; otitis externa

\section{INTRODUCTION}

Canine otitis externa and dermatitis are frequently encountered diseases in a veterinary practice. The etiology of canine otitis externa is complex and involves many factors which can be classified as: predisposing, primary and perpetuating. Microorganisms, both bacteria and yeasts, are considered perpetuating factors [2]. The associated microflora of otitic ears include most often bacteria (Staphylococcus spp., Pseudomonas aeruginosa, Proteus spp., Steptococcus spp.) and yeasts (Malassezia spp., Candida spp. and other) [18]. Malassezia yeasts also play an important 
role in the development of seborrheic, atopic and allergic dermatitis in dogs. Yeasts are known to be more frequently found in areas where there is an ample amount of sebum secretions [6]. These lipophilic yeasts may be isolated from normal ear canals and also healthy skin, but if environmental conditions are suitable, the otitis externa or dermatitis can be created by these pathogens [9]. So far, 16 species of Malassezia are known: M.dermatis, M.japonica, M.obtusa, M.restricta, M.yamatoensis, M.furfur, M.globosa, M.slooffiae, M.sympodialis, M.pachydermatis, M.caprae, M. equina, M.cuniculi, M. nana, M. brasiliensis sp. nov and M.psittaci sp. nov. [3]. Up to now, only M.pachydermatis $[1,4]$, M.furfur $[10,11,13]$ and M.obtusa in participation with M.furfur [10] have been identified in dogs. The preliminary diagnosis of Malassezia dermatitis and otitis is suggested by the typical clinical findings, such as erythema, greasiness, alopecia, lichenification, variable hyperpigmentation and marked pruritus, and by the identification of yeasts in specimens obtained from affected areas, which demonstrate the lack of response to treatment with antibiotics, corticosteroids and immunotherapy [20]. The definitive diagnosis is based upon yeast identification composed of phenotypic and genotypic methods. The phenotypic methods (biochemical and morphological characteristics) are time-consuming and are subject to variable interpretation. Genotypic identification (fingerprinting methods, DNA sequence analysis and restriction analysis of PCR amplicons) is necessary for the exact diagnosis [29].

The aim of this study was to identify Malassezia yeasts in dermatologically diseased dogs and to determine their prevalence.

\section{MATERIALS AND METHODS}

The survey was carried out on 300 dogs with skin lesions, otitis externa or inflammation of the anal sacs (174 male and 126 female). The ages of the animals ranged from 8 weeks to 14 years. The samples were collected from affected body sites (external ear canals, interdigital areas, cutaneous lesions, and anal sacs) of dogs with clinical manifestation, by using sterile cotton swabs (Fungi-Quick, Dispolab, SR). The samplings were acquired before employing any antimicrobial therapy, particularly from the affected areas with symptoms, such as seborrhea, erythema, alopecia, scaly plaques or pruritic lesions. The secretions of the anal sacs were sampled by using a lavage with $0.9 \%$ sodium chloride solution. The samples were inoculated on Sabouraud dextrose agar with chloramphenicol (SCA) (HiMedia Laboratories Pvt. Ltd., Mumbai, India), Modified Leeming \& Notman agar medium (MLNA) [19] and Modified Candida-Chrom agar (HIT) with Tween 40 [16] and incubated at $32^{\circ} \mathrm{C}$ for 7 days. The preliminary identification of yeasts was based on both the macroscopic appearance of the colonies and the microscopic cell morphology. Each sample was stained by Gram and examined by microscopy for the presence of the typical Malassezia yeast cells. More detailed identification was performed according to Ka nek o et al. [17]. DNA was recovered from solitary colonies grown on MLNA at $32^{\circ} \mathrm{C}$ for four days.

All phenotypically positive samples recognized as $\mathrm{Mal}$ assezia yeast cells were investigated by PCR-RFLP [14]. The Internal Transcribed Spacer 2 region (ITS2) was amplified by PCR using the ITS3 (5'-GCATCGATGAAGAACGCAGC- $\left.3^{\prime}\right)$ and ITS4 (5'-TCCTCCGCTTATTGATATGC-3') primers [30] (Life Technologies, California, USA). PCR was modified according to Gaita $n$ is et al. [15] and performed in a total volume of $50 \mu \mathrm{l}$. The reaction mixture consisted of $1 \times$ concetrated PCR Buffer (Life Technologies, California, USA), 3 mmol. ${ }^{-1} \mathrm{MgCl}_{2}$ (Life Technologies, California, USA), $15 \mu \mathrm{mol}$ of each primer (Life Technologies, California, USA), $0.1 \mathrm{mmol}$ of dNTPs (Thermo Fisher Scientific, Massachusetts, USA), 2.5 U of Taq polymerase (Life Technologies, California, USA) and $2 \mu$ of template DNA. Five $\mu$ of the PCR products were analyzed by electrophoresis in $1.5 \%$ agarose gel at $120 \mathrm{~V}$ for $1 \mathrm{~h}$; the gel was stained (GelRed, Biotium Inc., California, USA) and visualized under UV light. Lengths of the amplified DNA fragments were verified using GeneRuler 100bp DNA Ladder (Thermo Fisher Scientific, Massachusetts, USA) and ran simultaneously. The restriction endonucleases AluI, BanI and MspA1I (New England Biolabs, Massachusetts, USA) were used for digestion of the PCR products at $37^{\circ} \mathrm{C}$ for $3 \mathrm{~h}$ [16] in the amount of $10 \mathrm{U}$. Restriction fragments were analyzed in $3 \%$ GelRed stained agarose gel at $120 \mathrm{~V}$ for $2 \mathrm{~h}$ and were visualized by UV light. Lengths of the amplified DNA fragments were verified using Thermo Scientific GeneRuler Low Range DNA Ladder (Thermo Fisher Scientific, Massachusetts, USA). Reference strains of Malassezia spp. (M. cuniculi CBS 11721, M.pachydermatis CBS 1879, M. furfur CBS 4162, M. slooffiae CBS 7956, M. globosa CBS 7874, M. nana CBS 9557, M. sympodialis CBS 8334, 
M. equina CBS 9969, M. caprae CBS 10434) (CBS-KNAW

Fungal Biodiversity Centre Utrecht, Netherland) were used as a positive control.

\section{RESULTS}

Of the 300 animals examined, Malassezia yeasts were detected in 76 dogs by cultivation and microscopical methods (Table 1). From these positive animals, a total of 84 isolates were collected, of which 79 were identified as M.pachydermatis (six dogs had atopic dermatitis and also otitis externa with the occurrence of M.pachydermatis). Four isolates were identified as M.furfur (two M.furfur samples were isolates in association with M.pachydermatis) and one as M.nana. All phenotypically positive samples were confirmed by PCR-RFLP, obtaining the same results. In our group of dogs with clinical manifestations of disease,

Table 1. Prevalence of Malassezia species in diseased dogs

\begin{tabular}{|c|c|c|c|}
\hline & $\begin{array}{l}\text { Total number } \\
\text { of dogs }\end{array}$ & $\begin{array}{c}\text { Number of } \\
\text { positive dogs }\end{array}$ & $\begin{array}{c}\text { Prevalence } \\
{[\%]}\end{array}$ \\
\hline \multicolumn{4}{|c|}{ Clinical status } \\
\hline Diseased & 300 & 76 & 25.3 \\
\hline \multicolumn{4}{|c|}{ Sex } \\
\hline Male & 174 & 44 & 25.3 \\
\hline Female & 126 & 32 & 25.4 \\
\hline \multicolumn{4}{|c|}{ Age } \\
\hline$<1$ year & 54 & 13 & 24.1 \\
\hline $1-10$ years & 220 & 58 & 26.4 \\
\hline$>10$ years & 26 & 5 & 19.2 \\
\hline \multicolumn{4}{|c|}{ Type of ears } \\
\hline Pendulous & 180 & 59 & 32.8 \\
\hline Erect & 120 & 17 & 14.2 \\
\hline \multicolumn{4}{|c|}{ Diagnosis } \\
\hline Otitis externa & 125 & 45 & 36.0 \\
\hline Dermatitis & 106 & 26 & 24.5 \\
\hline $\begin{array}{l}\text { Interdigital } \\
\text { dermatitis }\end{array}$ & 55 & 9 & 16.4 \\
\hline $\begin{array}{l}\text { Inflammation } \\
\text { of anal sacs }\end{array}$ & 14 & 2 & 14.3 \\
\hline
\end{tabular}

the prevalence of Malassezia spp. was $25.3 \%$. The highest prevalence of Malassezia was determined in dogs with otitis externa (36.0\%), followed by dermatitis (24.5\%), interdigital dermatitis (16.4\%) and infected anal sacs (14.3\%). The Malasezia yeasts occurred most frequently in the group of dogs with pendulous ears $(32.8 \%)$ in comparison to dogs with erect ears (14.2\%). No differences related to gender or age were observed.

\section{DISCUSSION}

Due to the variability of the phenotypic methods for the precise identification of the pathogen, we used a genotypic method based on PCR-RFLP. This study demonstrated that RFLP applying restriction enzymes, which is one of several molecular techniques used for identification and classification of Malassezia yeasts, is a quick and accurate method.

From the microbiological perspective, Malassezia is considered to be the primary fungal pathogen in dogs [7]. Our results indicated that the prevalence of Malassezia spp. in diseased dogs was $25.3 \%$. On the other hand, Nard on $\mathrm{i}$ et al. [23] described a prevalence of $67.6 \%$ in dermatologically diseased dogs.

Ears are susceptible to unusual local conditions high humidity, presence of cerumen and less air circulation - which constitute an ideal environment for Malassezia growth. Otitis externa is not a life threatening disease but can be frustrating for both patients and owners. We detected a $36.0 \%$ prevalence of Malassezia species in the external ear canals of dogs with otitis externa. Cafa rchia et al. [5] isolated Malassezia yeasts from $57.3 \%$ of the dogs with otitis and from $28 \%$ of the dogs without otitis externa. Nardoni et al. [22] detected Malassezia spp. in 63.4\% of the dogs with otitis. In contrast to this, Sarierler and Kirkan [27], in their study of 234 dogs with otitis externa, found M.pachydermatis only in $5.12 \%$ of the samples and Campbell et al. [7] in 17\% of normal and diseased canine ears. According to the authors, the incidence of Malassezia varies and also different species of these yeasts were found. In our study, we identified 79 M.pachydermatis isolates, four M.furfur isolates and one M. nana from all positive samples. Similarly, Cafarchia et al. [6] reported in both, healthy dogs and in dogs with cutaneous lesions, a higher prevalence of $M$.pachydermatis than lipid dependent Malassezia species. Duarte et al. [12] identified 
only one atypical strain of M.furfur isolated from a dog. Also, other results suggest that in the external ear canals of 57 dogs with chronic otitis externa, lipid-dependent Malassezia species were isolated in only three dogs. These species were identified as M.furfur and M.obtuse, but showed atypical assimilation patterns [10]. Nardoni et al. [22] isolated only M. pachydermatis in their study of 41 dogs.

In our study, we recorded the difference in occurrence of Malassezia yeasts in pendulous ears compared to erect ears. We suspected that the type of ears (pendulous or erect) may influences the prevalence of Malassezia occurrence. Kumar et al. [18] reported that the percentage of dogs with long pendulous ears and otitis externa was similar to the percentage of dogs with erect ears and medium hair on the ears, but Cafarchia et al. [5] reported that dogs with pendulous ears showed a higher incidence of infection than dogs with erect ears.

The most frequent conditions that may contribute to Malassezia overgrowth on skin are: hormonal imbalance, keratinization defects, excessive production of sebum, bacterial infections and hypersensitivity processes [28]. Other important causes of Malassezia occurrence in our patients were also dermatitis (24.5\%) and interdigital dermatitis (16.4\%). Nardoni et al. [22] considered the interdigital space to be the place with the highest Malassezia prevalence, but it was not confirmed in our results.

Our results show that $14.3 \%$ of dogs with inflammation of the anal sacs were positive for M.pachydermatis. Cytological quantification of Malassezia in the anal sac contents of healthy dogs revealed a low occurrence of yeasts, with only $12.5 \%$ in the examined dogs and $10 \%$ of the anal sacs, demonstrating the presence of Malassezia yeasts [25].

Some authors described a predisposition of Malassezia infection to be dependent upon the age of dogs $[8,21]$. We did not find a difference between the occurrence of Malassezia spp. and the age of the diseased dogs, which was similar to the results of Plant et al. [26] and Nobre et al. [24].

\section{CONCLUSIONS}

In conclusion, all isolated Malassezia species in our study were identified both phenotypically and genotypically as M.pachydermatis, except for four isolates that were identified as $M$. furfur and one isolate, which was identified as M.nana. No other species of Malassezia was found.
The highest prevalence of Malassezia was detected in dogs with otitis externa. Our study confirmed that Malassezia remains the most prevalent yeast found in the dog and that the occurrence of other species is infrequent.

\section{ACKNOWLEDGEMENTS}

This work was supported by the Slovak Research and Development Agency under the contract No. APVV-15-0377.

\section{REFERENCES}

1. Aizawa, T., Kano, R., Nakamura, Y., Watanabe, S., Hasegawa, A., 1999: Molecular heterogeneity in clinical isolates of Malassezia pachydermatis from dogs. Vet. Microbiol., 70, 67-75.

2. August, J.R., 1988: Otitis externa, a disease of multifactorial etiology. Vet. Clin. North. Am. Small Anim. Pract., 18, 731-742.

3. Cabañes, F. J., Coutinho, S. D., Puig, L., Bragulat, M. R., Castellá, G., 2016: New lipid-dependent Malassezia species from parrots. Revista Iberoamericana De Micologia, 33, 92-99.

4. Cafarchia, C., Latrofa, M.S., Testini, G., Parisi, A., Guillot, J., Gasser, R.B., Otranto, D., 2007: Molecular characterization of Malassezia isolates from dogs using three distinct genetic markers in nuclear DNA. Mol. Cell Probes., 21, 229-238.

5. Cafarchia, C., Gallo, S., Capelli, G., Otranto, D., 2005: Occurrence and population size of Malassezia spp. in the external ear canal of dogs and cats both healthy and with otitis. Mycopathologia, 160, 143-149.

6. Cafarchia, C., Gallo, S., Romito, D., Capelli, G., Chermette, R., Guillot, J., Otranto, D., 2005: Frequency, body distribution, and population size of Malassezia species in healthy dogs and in dogs with localized cutaneous lesions. J. Vet. Diagn. Invest., 17, 316-322.

7. Campbell, J. J., Coyner, K.S., Rankin, S.C., Lewis, T.P., Schick, A.E., Shumaker, A.K., 2010: Evaluation of fungal flora in normal and diseased canine ears. Vet. Dermatol., 21, 619-625.

8. Carlotti, D. N., Taillieu-Le Roy, S., 1997: Lotite externe chez le chien: étiologie et clinique, revue bibliographyque et étude retrospective portant sur 752 cas. Pratique Médicale et Chirurgicale de l'Animal de Compagnie, 32, 243-257.

9. Chen, T. A., Hill, P. B., 2005: The biology of Malassezia organisms and their ability to induce immune responses and skin disease. Vet. Dermatol., 16, 4-26. 
10. Crespo, M.J., Abarca, M.L., Cabañes, F. J., 2000: Atypical lipid-dependent Malassezia species isolated from dogs with otitis externa. J. Clin. Microbiol., 38, 2383-2385.

11. Crespo, M.J., Abarca, M.L., Cabañes, F.J., 2002: Occurrence of Malassezia spp. in horses and domestic ruminants. Mycoses, 45, 333-337.

12. Duarte, E. R., Lachance, M.A., Hamdan, J. S., 2002: Identification of atypical strains of Malassezia spp. from cattle and dog. Can. J. Microbiol., 48, 749-752.

13. Duarte, E. R., Resende, J. C. P., Hamdan, J. S., 2009: Characterization of typical and atypical Malassezia spp. from cattle and dog by random amplified polymorphic DNA analysis. Arg. Inst. Biol., 76, 157-164.

14. Gaitanis, G., Velegraki, A., 2006: Verifiable single nucleotide polymorphisms of the internal transcribed spacer 2 region for the identification of 11 Malassezia species. J. Dermatol. Sci., 43, 214-217.

15. Gaitanis, G., Velegraki, A., Frangoulis, E., Mitroussia, A., Tsigonia, A., Tzimogianni, A. et al., 2002: Identification of Malassezia species from patient skin scales by PCR-RFLP Clin. Microbiol. Infect., 8, 162-173.

16. Kaneko, T., Makimura, K., Sugita, T., Yamaguchi, H., 2006: Tween 40-based precipitate production observed on modified chromogenic agar and development of biological identification kit for Malassezia species. Med. Mycol., 44, 227-231.

17. Kaneko, J., Makimura, K., Abe, I., Shiota, R., Nakamura, Y., Kano, R., et al., 2007: Revised culture-based system for identification of Malassezia species. J. Clin. Microbiol., 45, 3737-3742.

18. Kumar, A., Singh, K., Sharma, A., 2002: Prevalence of Malassezia pachydermatis and other organisms in healthy and infected dog's ears. Israel J. Vet. Med., 57, 145-148.

19. Leeming, J. P., Notman, F. H., 1987: Improved methods for isolation and enumeration of Malassezia furfur from human skin. J. Clin. Microbiol., 25, 2017-2019.

20. Mason, K. V., 1993: Cutaneus Malassezia. In Griffin, C.E., Kwochka, K. W., MacDonald, J. M. (Ed.): Current Veterinary Dermatology, Mosby Year book, St. Louis, 44-48.

21. Mauldin, E. A., Scott, D. W., Miller, W. H., 1997: Malassezia dermatitis in the dog: a retrospective histopathological and immunopathological study of 86 cases (1990-95). Vet. Dermatol., 8, 191-202.
22. Nardoni, S., Dini, M., Taccini, F., Mancianti, F., 2007: Occurrence, distribution and population size of Malassezia pachydermatis on skin and mucosae of atopic dogs. Vet. Microbiol., 122, 172-177.

23. Nardoni, S., Mancianti, F., Corazza, M., Rum, A., 2004: Occurrence of Malassezia species in healthy and dermatologically diseased dogs. Mycopathologia, 157, 383-388.

24. Nobre, M.O., Castro, A.P., Nascente, P.S., Ferreiro, L., Meireles, M.C., 2001: Occurrence of Malassezia pachydermatis and other infectious agents as cause of external otitis in dogs from Rio Grande do Sul State, Brazil (1996/1997). Braz. J. Microbiol., 32, 245-249.

25. Pappalardo, E., Martino, P. A., Noli, C., 2002: Macroscopic, cytological and bacteriological evaluation of anal sac content in normal dogs and in dogs with selected dermatological diseases. Vet. Dermatol., 13, 315-322.

26. Plant, J. D., Rosenkrantz, W.S., Griffin, C.E., 1992: Factors associated with and prevalence of high Malassezia pachydermatis numbers on dog skin. J. Am. Vet. Med. Assoc., 201, $879-882$.

27. Sarierler, M., Kirkan, S., 2004: Microbiological diagnosis and therapy of canine otitis externa. Veteriner Cerrahi Dergisi, 10, 11-15.

28. Scott, D. W., Miller, W.H., Griffin, C.E., 2001: Disease of eyelids, claws, anal sacs and ears. In Miller and Kirk's Small Animal Dermatology. Philadelphia, PA, WB Saunders Co, $1209-1216$

29. Sihelská, Z., Vázci, P., Čonková, E., Holoda, E., Pistl, J., Badlík, M., 2013: Laboratory diagnostic methods for the identification of Malassezia species. Folia Veterinaria, 57, $135-141$

30. White, T. J., Bruns, T., Lee, S., Taylor, J. W., 1990: Amplification and direct sequencing of fungal ribosomal RNA genes for phylogenetics. In Innis, M. A., Gelfand, D. H., Sninsky, J. J., White, T. J. (Ed.): PCR protocols: A Guide to Methods and Applications. Academic Press, San Diego, 315-322.

Received February 8, 2017

Accepted April 7, 2017 